\title{
Click-Chemistry as a Powerful Tool for the Construction of Functional Poly(para-phenyleneethynylene)s: Comparison of Pre- and Postfunctionalization Schemes
}

\author{
Brian C. Englert, Selma Bakbak and Uwe H. F. Bunz* \\ School of Chemistry and Biochemistry \\ Georgia Institute of Technology, Atlanta, GA 30332, USA \\ Email: uwe.bunz@chemistry.gatech.edu fax int.+1-404-385-1795 \\ SUPPORTING INFORMATION
}




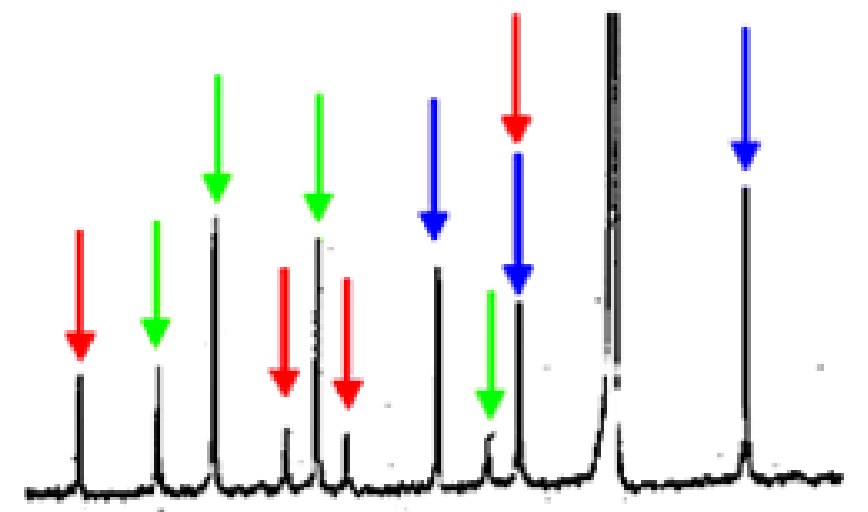

5
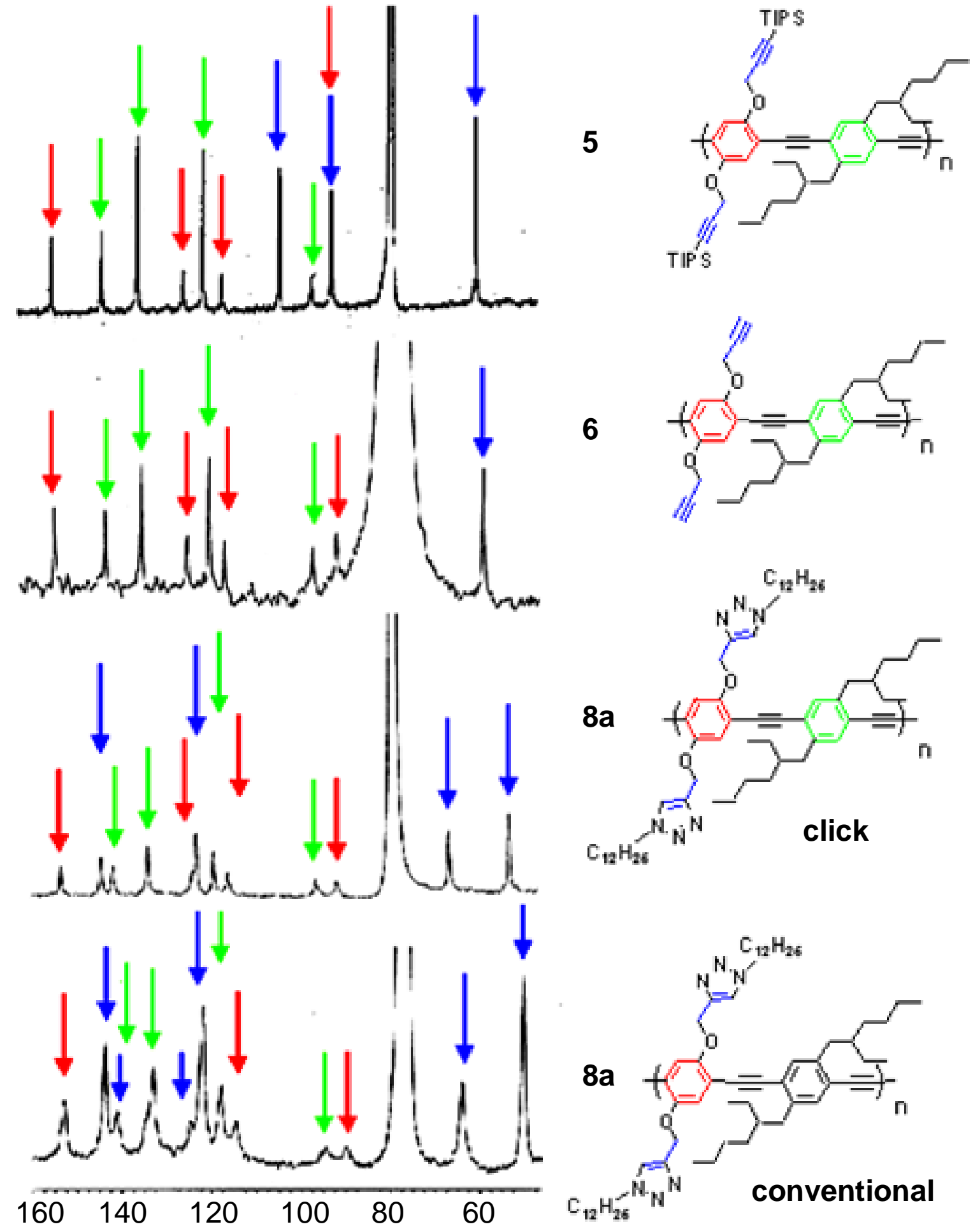

Figure. ${ }^{13} \mathrm{CNMR}$ of polymers 5, 6, 8a (post), and 8a (pre) (top to bottom). 


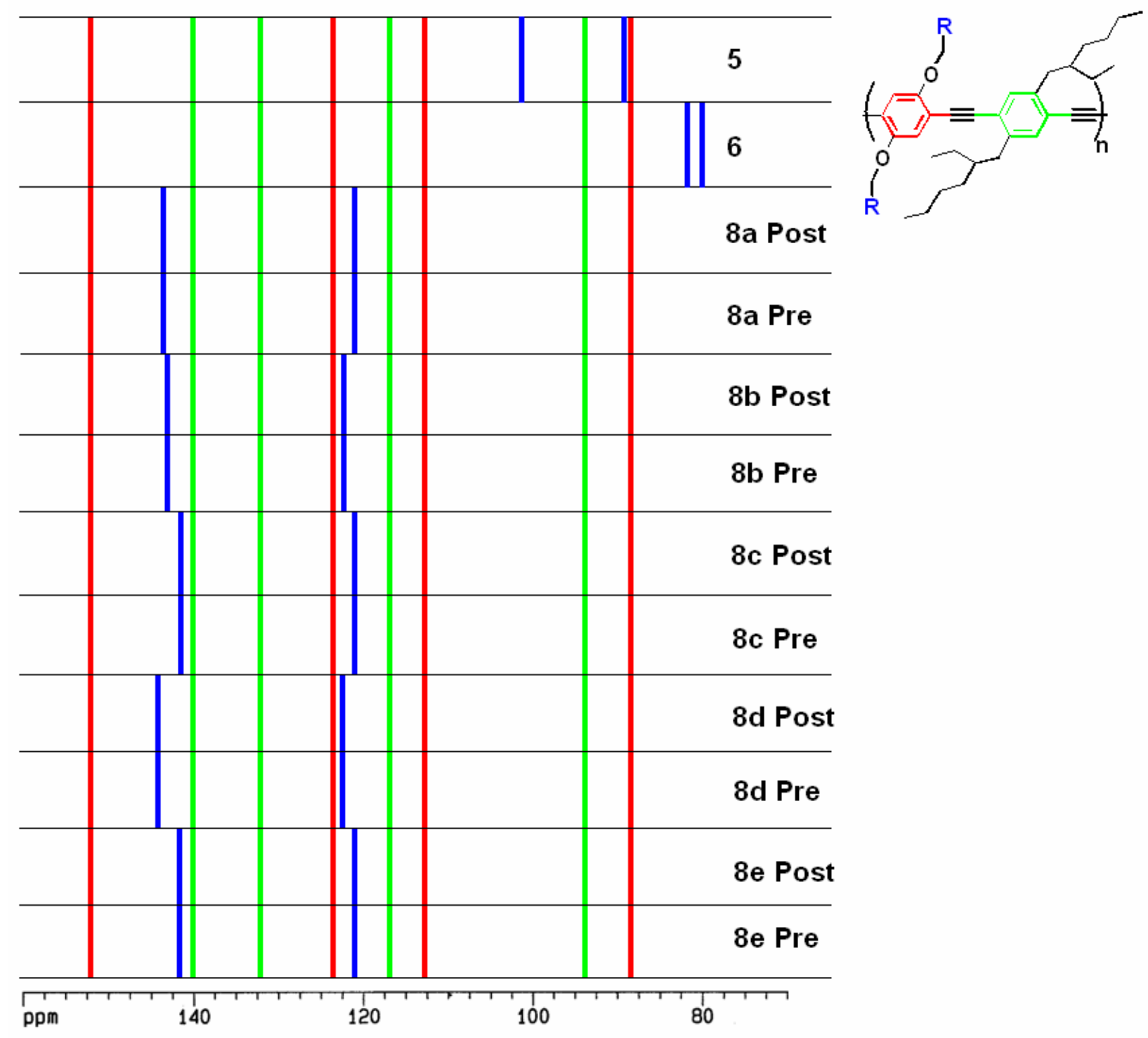

Figure. Bar chart of ${ }^{13} \mathrm{C}$ NMR spectra of polymers 5, 6, and 8a-e. 
